\title{
REFLECTIONS
}

\section{Towards a New Understanding of Provider Continuity}

Stephen A. Buetow, PbD

Department of General Practice and Primary Care, University of Auckland, Auckland, NZ

\begin{abstract}
Provider continuity is in need of an expanded definition that is not exclusively clinician centered. Currently, provider continuity is defined by visits over time to the same clinician. Many patients and informal caregivers, however, are coproviders of health care, not merely consumers. As a result, provider continuity will not happen if there is a lack of consistency in who attends with or for the patient during successive visits. Such fragmentation may weaken knowledge of the patient and information exchange. Consequently, there is a need to redefine provider continuity to mean that the same attendees visit the same clinician(s), service, or facility as an uninterrupted succession of events. More than semantic quibbling, the proposed reconceptualization challenges the foundation of family medicine in terms of the values and language by which the discipline defines itself in clinician-centered ways. The change required has implications for practice and research.
\end{abstract}

Ann Fam Med 2004;2:509-511. DOI: 10.1370/afm.115.

$\mathrm{F}$ amily medicine needs a new dictionary. Essential attributes of the structure and delivery of family medicine continue to be defined in terms of what individual clinicians, health care teams, health services, and facilities can do for individual patients. This clinician-centric perspective potentially devalues contributions from patients and their informal caregivers and limits our understanding of key concepts, their effects, and health policies for achieving them. These contributions are especially important given the lack of evidence for consistent health gains from provider continuity. ${ }^{1,2}$

This essay explores the concept of provider continuity as one dimension of continuity of care. Provider continuity, also known as longitudinality, ${ }^{3}$ was recently defined by Freeman and colleagues as "seeing the same professional."4 I aim to show how a fundamental shift is required, not only in the meaning of provider continuity and, by inference, other defining attributes of family medicine, but also in the social values underpinning their conceptualization in exclusively clinician-centered ways and influencing research and practice. ${ }^{5}$

A focus on provider continuity may "inadvertently exclude the patient perspective" by not "incorporating the needs and experiences of those who use services." ${ }^{16}$ Although Schers and colleagues ${ }^{7}$ obtained patients' views on personal continuity, they defined this concept themselves as "seeing the personal doctor." Starfield ${ }^{3}$ highlighted the importance of patient perceptions of attaining arrangements for continuity of care. In 2 respects, however, I believe she did not go far enough.

First, patients and those who accompany them during visits are principal primary health care workers. ${ }^{8}$ They are coproducers or coproviders of family medicine, not merely consumers. ${ }^{9}$ Second, a patient perspective challenges the belief that provider continuity "is experienced by an 
individual" patient. ${ }^{10} \mathrm{~A}$ family member commonly accompanies the patient, ${ }^{11,12}$ and in some of these circumstances the family member is an informal caregiver, such as when the patient is a young child. Here the issue of continuity goes beyond the patient to refer to whether the same caregiver(s) accompany the patient during successive visits. Provider continuity will not happen if different caregivers attend each time, fragmenting clinician interaction with the patient or those who care for, speak for, or decide for the patient, and thereby reducing the consistency of the care.

In referring to the "consistency of [clinician] personnel," Reid and colleagues ${ }^{10}$ made no reference to the consistency of attendees, yet provider continuity implies it. Besides weakening provider continuity, lack of consistency in who attends with or without the patient (for example, a mother attending without, but for, her child) can weaken other dimensions of continuity of care and, as a result, be made worse. These other dimensions have been labeled informational continuity and relational or interpersonal continuity, ${ }^{10,13,14}$ where informational continuity refers to accumulated knowledge and information transfer within and outside visits, and relational continuity signifies the establishment and maintenance of a therapeutic relationship. ${ }^{10}$ Continuity of care can be weakened because the clinician $(s)^{15}$ and caregivers ${ }^{9}$ are hindered from providing, in "sustained partnership,"16 coordinated care that meets the demands of an ongoing sense of responsibility to the patient.

There is a need, therefore, to expand the meaning of provider continuity to accommodate who attends with, or for, the patient during successive visits. For young children, some older persons, and various other dependent patients, including those deemed incompetent and those in need of a language interpreter, provider continuity should be redefined to mean that the same attendees make visits to the same clinician(s), service, or facility as an uninterrupted succession of events over time. These attendees include the patient and informal caregiver or other support person(s). In these terms, provider continuity requires that, for example, a young child be accompanied by the same, rather than a different caregiver, for each visit. This definition challenges the current understanding of provider continuity ${ }^{10}$ and, by logical extension, the very foundation of family medicine in terms of the clinician-centered values and language by which this discipline continues to define itself.

Change in who accompanies the patient to a family physician, or some other clinician, may reflect family circumstances that include divorced or separated parents, parents in paid work outside the household, foster care, institutionalization, the family care of an older or disabled person, and the cultural group(s) of the patient and caregiver. In New Zealand, for example, many indigenous Maori and Pacific Island children move frequently between families. ${ }^{17,18}$ The caregivers within each of these families may visit their own family physician(s), signifying for the children a lack of provider continuity among caregivers and physicians. Similar situations may occur elsewhere, such as in the United States, where there are 874,000 persons selfidentified as Native Hawaiian and other Pacific Islanders ( $0.3 \%$ of the US population) in the April 2000 census. ${ }^{19}$

What implications does this change have for all health systems? As discussed, the meaning of provider continuity and the values that underpin it need to become more patient-focused or at least more balanced. It is necessary to redefine provider continuity in the manner suggested above, distinguish between clinician continuity and caregiver continuity, and reveal essential features of each type of continuity. Doing so would have theoretical value, extending the meaning of the term provider; acknowledging lay influences on continuity of care; and implying that other attributes of family medicine, such as comprehensiveness of care and coordination of care, also require reconceptualization in much less clinician-centered ways.

Second, to have practical benefit, research on caregiver continuity is needed to document the extent to which this type of continuity takes place, elucidate when and why it occurs, indicate the possibilities it defines for coproducing health care, and evaluate its effects on health care delivery and patient health. Such research should help to explain why potential benefits of provider continuity have not been consistently reported. It should also indicate opportunities for new policies and practices that can enhance informationexchange, an ongoing relationship between caregivers and clinicians, and health outcomes for patients.

If lack of caregiver continuity is shown to influence health care adversely, it will be important to evaluate strategies for reducing this effect. One strategy might be for family physicians to encourage the same support persons to accompany the patient each time-not to mention visit one clinician, team, or facility - and then to enable these attendees to help codeliver family medicine. A second strategy could involve the use of caregiver-held health records to aid improvements in caregiver coordination. The need for research on provider continuity, as redefined in this essay, will continue to grow as population aging augments the proportions of dependent older people and of caregivers needing support.

To read or post commentaries in response to this article, see it online at http://www.annfammed.org/cgi/content/full/2/5/509. 
Key words: Continuity of patient care; health care providers; caregivers; theory; delivery of health care; health services research; family systems

Submitted July 2, 2003; submitted, revised, December 4, 2003; accepted December 15, 2003.

\section{References}

1. Starfield B. Continuous confusion? [editorial]. Am J Pub Health. 1980;70:117-119.

2. Fleming D. Continuity of care: a concept revisited. Eur J Gen Pract. 2000;6:140-145.

3. Starfield B. Primary Care: Balancing Health Needs, Services and Technology. New York, NY: Oxford University Press; 1996.

4. Freeman G, Shepperd S, Richards S, Pitman P, Sand P. Continuity of care. Report of a scoping exercise for the National Co-ordinating Centre for NHS Service Delivery and Organisation R \& D (NCCSDO). London: NCCSDO; 2001.

5. Epstein S. Values from the perspective of cognitive-experiential selftheory. In: Eisenberg N, Reykowshi J, Staub E, eds. Social and Moral Values. New Jersey: Lawrence Erlbaum; 1989.

6. Shepperd S, Richards S. Continuity of care - a chameleon concept. J Health Serv Res Policy. 2002;7:1301-1331.

7. Schers H, Webster S, van den Hoogen H, Avery A, Grol R, van den Bosch W. Continuity of care in general practice: a survey of patients' views. Br J Gen Pract. 2002;52:459-462.

8. Stacey M. The Sociology of Health and Healing: A Textbook. London: Unwin Hyman; 1988.
9. Buetow S. The scope for patient involvement in doctor-patient consultations in primary care: the rights, responsibilities and preferences of patients. J Med Ethics. 1998;24:243-247.

10. Reid R, Haggerty J, McKendry R. Defusing the confusion: concepts and measures of continuity of healthcare. Final Report. Ottawa: Canadian Health Services Research Foundation; 2002:3.

11. Main DS, Holcomb S, Dickinson P, Crabtree B. The effect of families on the process of outpatient visits in family practice. J Fam Pract. $2001 ; 50: 888$

12. Flocke S, Goodwin MA, Stange KC. The effect of a secondary patient on the family practice visit. J Fam Pract. 1998;46:429-434.

13. Hennen BK. Continuity of care in general practice. 1: dimensions of continuity. J Fam Pract. 1975:2:371-372

14. Saultz J. Defining and measuring interpersonal continuity of care. Ann Fam Med. 2003;1:134-143.

15. McWhinney I. A Textbook of Family Medicine. 2nd ed. New York: Oxford University Press; 1997

16. Donaldson M, Yordy K, Lohr K, Vanselow N, eds. Primary Care: America's Health in a New Era. Washington DC: National Academy Press; 1996.

17. Metge J. New Growth From Old. The Whanau in the Modern World. Wellington: Victoria University, 1995.

18. Ma'ia'i S. Barriers to Compliance With Diabetes Care Among Saamoans in Auckland [Thesis]. Auckland: University of Auckland; 2003.

19. Grieco EM. The Native Hawaiian and Other Pacific Islander Population: 2000. Washington DC: US Census Bureau; 2001. 